\title{
Preface
}

\section{Heterogeneous catalysis in commodity and fine chemicals synthesis}

This issue of Catalysis Today is one of the three special issues based on a selection of the papers presented at the Third Conference of Indo-Pacific Catalysis Association (IPCAT-3), which was jointly held with the 21st Taiwan Symposium on Catalysis and Reaction Engineering (TSCRE-2003) during 16-18 November 2003 at National Taiwan University, Taipei, Taiwan. The conference of IndoPacific Catalysis Association is usually held jointly with the national conference of the host country. It is aimed at providing an opportunity to close link and to stimulate cooperation among catalysis researchers from different countries, especially in the Indo-Pacific Rim. Following the success of the two former conferences in Cape Town, South Africa (January 1998) and Pune, India (January 2001), IPCAT-3 had eminent plenary and invited lectures as well as renowned scholars presented their latest findings and recent development in the following fields:

- $\mathrm{C}_{1}$ chemistry, including activation of $\mathrm{CH}_{4}, \mathrm{CO}$ and $\mathrm{CO}_{2}$;

- environmental sciences;

- energy and resources;

- fine chemicals synthesis;

- acid and base catalysis;

- characterization and spectroscopy;

- synthesis and fabrication of catalytic materials;

- reaction engineering;

- bio-catalysis.

This issue contains 16 papers in relation to "Heterogeneous Catalysis in Commodity and Fine Chemicals Synthesis". Heterogeneous catalysts have been widely used in industrial processes, and to a large extent are concerned with the production of commodity chemicals. Still, there are always needs to increase the efficiency of known processes, to lower down the cost and to reduce the environmental hazard by the improvement in catalytic systems. On the other hand, the applications of heterogeneous catalysis to fine chemicals synthesis become even promising as mesoporous molecular sieves were discovered a decade ago. The issue started with a review paper by H.H. Kung, which evaluated the impact of nanotechnology on heterogeneous catalysis. Examples were presented to illustrate what nanotechnology could do for heterogeneous catalysis to help achieve the goal of designing catalysts for perfect selectivity in a chemical reaction. Seven papers concern the development of new catalytic systems for fine chemical synthesis. Also presented in this issue are eight papers studying zeolites and supported metal catalysts in the synthesis of commodity chemicals.

A special acknowledgment is made to the many colleagues who acted as referees and to the authors for the time and effort they gave to present their research at the conference and in preparing their manuscripts. We would also like to thank the organizing committee of IPCAT-3, especially Prof. Shang-Bin Liu, in organizing the conference.

Soofin Cheng

Department of Chemistry, National Taiwan University No. 1, Roosevelt Road, Sec. 4, Taipei 106, Taiwan Corresponding author. Fax: +886 223636359 E-mail address: chem1031@ccms.ntu.edu.tw

An-Nan Ko Tunghai University, Taichung, Taiwan Available online 25 August 2004 